\title{
Timing of disease occurrence and hepatic resection on long-term outcome of patients with neuroendocrine liver metastasis
}

\author{
Xu-Feng Zhang MD, PhD ${ }^{1,2}$ | Eliza W. Beal MD² | Matthew Weiss MD $^{3}$ (D) \\ Luca Aldrighetti MD ${ }^{4}$ | George A. Poultsides $M^{5}$ | Todd W. Bauer MD ${ }^{6}$ | \\ Ryan C. Fields MD ${ }^{7}$ | Shishir K. Maithel MD ${ }^{8}$ Hugo P. Marques MD | \\ Timothy M. Pawlik MD, MPH, PhD²
}

\author{
${ }^{1}$ Department of Hepatobiliary Surgery and \\ Institute of Advanced Surgical Technology \\ and Engineering, The First Affiliated Hospital \\ of Xi'an Jiaotong University, Xi'an, China \\ ${ }^{2}$ Department of Surgery, The Ohio State \\ University Wexner Medical Center, Columbus, \\ Ohio \\ ${ }^{3}$ Department of Surgery, Johns Hopkins \\ Hospital, Baltimore, Maryland \\ ${ }^{4}$ Department of Surgery, Scientific Institute \\ San Raffaele, Vita-Salute San Raffaele \\ University, Milan, Italy \\ ${ }^{5}$ Department of Surgery, Stanford University, \\ Stanford, California \\ ${ }^{6}$ Department of Surgery, University of \\ Virginia, Charlottesville, Virginia \\ 7 Department of Surgery, Washington \\ University, School of Medicine, St Louis, \\ Missouri \\ ${ }^{8}$ Department of Surgery, Emory University, \\ Atlanta, Georgia \\ ${ }^{9}$ Department of Surgery, Curry Cabral \\ Hospital, Lisbon, Portugal

\section{Correspondence} \\ Timothy M. Pawlik, MD, MPH, PhD, FACS, \\ FRACS (Hon.) Professor and Chair, \\ Department of Surgery, The Urban Meyer III \\ and Shelley Meyer Chair for Cancer Research, \\ Professor of Surgery, Oncology, Health \\ Services Management and Policy, The Ohio \\ State University, Wexner Medical Center, \\ 395 W. 12th Ave., Suite 670, Columbus, $\mathrm{OH}$. \\ Email: tim.pawlik@osumc.edu
}

Background and Objectives: The objective of the study was to evaluate the impact of timing of disease occurrence and hepatic resection on long-term outcome of neuroendocrine liver metastasis (NELM).

Methods: A total of 420 patients undergoing curative-intent resection for NELM were identified from a multi-institutional database. Date of primary resection, NELM detection and resection, intraoperative details, disease-specific (DSS), and recurrencefree survival (RFS) were obtained.

Results: A total of 243 (57.9\%) patients had synchronous NELM, while 177 (42.1\%) developed metachronous NELM. On propensity score matching (PSM), patients with synchronous versus metachronous NELM had comparable DSS (10-year DSS, 76.2\% vs $85.9 \%, P=0.105$ ), yet a worse RFS (10-year RFS, 34.1\% vs 59.8\%, $P=0.008$ ). DSS and RFS were comparable regardless of operative approach (simultaneous vs staged, both $P>0.1)$. Among patients who developed metachronous NELM, no difference in longterm outcomes were identified between early ( $\leq 2$ years, $n=102,57.6 \%)$ and late $(>2$ years, $n=68,42.4 \%$ ) disease on PSM (both $P>0.1$ ).

Conclusions: Patients with synchronous NELM had a higher risk of tumor recurrence after hepatic resection versus patients with metachronous disease. The time to development of metachronous NELM did not affect long-term outcome. Curativeintent hepatic resection should be considered for patients who develop NELM regardless of the timing of disease presentation.

\section{KEYWORDS}

metachronous, neuroendocrine liver metastasis, synchronous

\section{1 | INTRODUCTION}


The liver is the most common site for the development of metastasis. In fact, approximately $60-90 \%$ of patients with NET develop synchronous or metachronous neuroendocrine liver metastasis (NELM) during the course of their disease. ${ }^{2,3}$ NELM can sometimes cause severe hormonal symptoms and dysfunction of the liver. ${ }^{4}$ As such, the presence of NELM can be associated with a poor quality of life and a worse long-term prognosis. ${ }^{4,5-7}$ While surgical resection is the main curative option for NELM, many patients will recur with either locally advanced or metastatic disease. ${ }^{1}$

Even in the presence of extensive bilateral disease, hepatic resection offers the best therapeutic option for NELM, providing significant symptomatic relief and an improvement in survival. $^{1,3,6,8,9}$ Similar to the surgical approach to colorectal liver metastasis (CRLM), the timing of NELM occurrence and hepatic resection may be determinants of long-term outcomes of patients. For example, among patients with CRLM, synchronous disease presentation has been associated with less favorable tumor biology and a shorter long-term survival compared with patients who had metachronous disease. ${ }^{10-13}$ Among patients who have synchronous CRLM, whether to perform a simultaneous or staged hepatic resection has also been a topic of debate. ${ }^{14,15}$ While simultaneous resection had traditionally been associated with higher morbidity and mortality, ${ }^{16,17}$ more recent studies have reported that simultaneous resection can be performed safely with comparable postoperative mortality, morbidity, and long-term outcomes, as well as a shorter hospital stay and lower health care costs. ${ }^{18-20}$ Unlike CRLM, the impact of presentation (ie, synchronous vs metachronous), as well as operative approach of synchronous disease (ie, simultaneous vs stage), has not been well examined for patients with NELM. Therefore, the objective of the present study was to define the long-term outcomes of patients with synchronous versus metachronous NELM, assess the impact of simultaneous versus staged resection for synchronous NELM, as well as to investigate the long-term prognosis of early and late metachronous NELM using a large multi-institutional, international database.

\section{2 | MATERIALS AND METHODS}

\section{1 | Patients}

Between 1990 and 2015, a total of 547 patients undergoing curativeintent hepatectomy for NELM were identified from a multiinstitutional database. Participating institutions included Johns Hopkins Hospital, Baltimore, MD; Scientific Institute San Raffaele, Vita-Salute San Raffaele University, Milan, Italy; Stanford University, Stanford, CA; University of Virginia, Charlottesville, VA; Washington University, School of Medicine, St Louis, MO; Curry Cabral Hospital, Lisbon, Portugal, and Emory University, Atlanta, GA. All NELM diagnoses were confirmed histologically. Patients with unresectable primary NET $(n=70)$, macroscopic positive surgical margins (R2 resection, $n=55)$, and in-hospital death $(n=2)$ were excluded. A total of 420 patients who underwent a simultaneous or staged RO/R1 resection for NELM were included in the analytic cohort (Figure 1). The Institutional Review Boards of each participating institution approved the study.

\subsection{1 | Data collection, definition, and follow up}

Data on clinical, pathological, and operative details were collected for each patient pertaining to both the primary tumor and NELM. Synchronous NELM was defined as liver metastasis identified at or before the surgery for the patient's primary NET. Metachronous NELM was defined as detectable NELM following treatment of the primary NET. ${ }^{12,21}$ Simultaneous resection was defined as a concomitant resection of both the primary NET and NELM, while staged resection was defined as resection of the primary and NELM at separate operative times. Data regarding receipt of pre- and post-operative adjuvant octreotide treatment and chemotherapy were recorded. For all study groups, NELM disease-specific survival (DSS) and recurrence-free survival (RFS) were calculated from the date of hepatic resection for NELM. Recurrence was defined as suspicious imaging findings or a biopsy-proven intra- and/or extra-hepatic NET tumor.

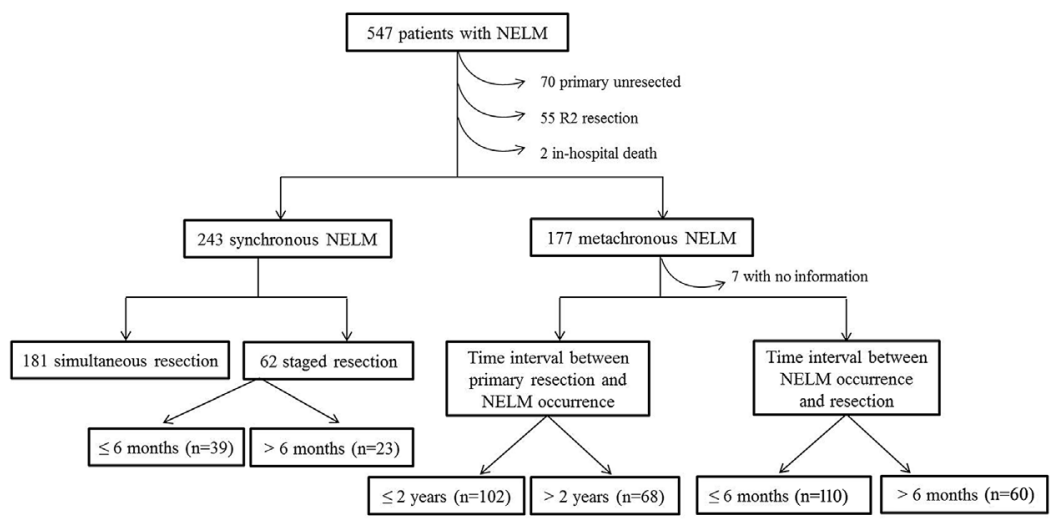

FIGURE 1 A diagram of patient inclusion and study scenario. NELM, neuroendocrine liver metastasis 


\subsection{2 | Statistical analysis}

Continuous variables were expressed as medians with interquartile ranges (IQR), while categorical variables were expressed as numbers and percentages. Variables were compared between groups with the Mann-Whitney $U$ test, Chi-squared test, or Fisher exact test, as appropriate. Survival was evaluated using Kaplan-Meier curves with logrank tests. Odds ratio (OR) or hazard ratio (HR) and $95 \%$ confidence interval $(\mathrm{Cl})$ were calculated as appropriate. Univariate and multivariable Cox regression models were used to determine factors associated with disease-specific and recurrence-free survival. Propensity score matching (PSM) was used to adjust for differences in baseline characteristics between groups. Specifically, variables potentially affecting long-term outcomes were derived from multivariable logistic regression analysis and propensity score matching was performed. In all analyses, a twotailed $P$ value $<0.05$ was considered statistically significant. Statistical analyses were performed using SPSS 22.0 (Chicago, IL).

\section{3 | RESULTS}

\subsection{Synchronous versus metachronous NELM: Impact on long-term outcome}

Among the 420 patients with NELM, 243 (57.9\%) patients had synchronous disease, while 177 (42.1\%) developed metachronous NELM. Patients with synchronous NELM were more likely to be male, have functional NETs and present with clinical symptoms (Table 1). Patients with synchronous NELM also had a higher incidence of primary NET lymph nodes metastasis (synchronous: $56.8 \%$ vs metachronous: $40.7 \% ; P=0.007$; OR $1.8,95 \% \mathrm{Cl} 1.2-2.7$ ), and were more likely to have been treated with either a somatostatin analogue or cytotoxic chemotherapy (synchronous: $30.9 \%$ vs metachronous: $20.9 \% ; P=0.023 ;$ OR $1.7,95 \% \mathrm{Cl} 1.2-2.7$ ) prior to hepatic surgery. In contrast, extent of hepatic resection, surgical margin status, and receipt of adjuvant therapy were no different among patients who presented with synchronous versus metachronous disease (all $P>0.05$ ) (Table 1).

Compared with patients who had metachronous disease, patients with synchronous NELM had a similar DSS (10-year DSS, synchronous: $70.8 \%$ vs metachronous: $77.1 \%, P=0.329$; HR 1.3 , $95 \% \mathrm{Cl}$ 0.8-2.0; Figure 2A), yet a worse RFS (10-year RFS, synchronous: $33.6 \%$ vs metachronous: $46.8 \%, P=0.027$; HR 1.4, $95 \% \mathrm{Cl} 1.1-1.8$; Figure 2B). On propensity score matching that accounted for primary and NELM tumor characteristics, nodal status, surgical procedure, and margin status (Supplementary Table S1), patients with synchronous versus metachronous NELM had comparable DSS (10-year DSS, synchronous: $76.2 \%$ vs metachronous: $85.9 \%, P=0.105$; HR $2.0,95 \% \mathrm{Cl} 0.8-4.9$; Figure $2 \mathrm{C}$ ), yet a worse RFS (10-year RFS, synchronous: $34.1 \%$ vs metachronous: $59.8 \%, P=0.008$; HR 1.8, 95\% Cl 1.2-2.9; Figure 2D).

Factors associated with DSS among patients undergoing curative resection for NELM included characteristics of the primary NET (functional vs non-functional, $\mathrm{HR} 0.2,95 \% \mathrm{Cl} 0.1-0.8, P=0.025$; poor

TABLE 1 Clinical and pathological characteristics of patients with synchronous and metachronous neuroendocrine liver metastasis (NELM) undergoing curative-intent surgery

\begin{tabular}{|llll|}
\hline & $\begin{array}{l}\text { Synchronous } \\
(\boldsymbol{n}=243)\end{array}$ & $\begin{array}{l}\text { Metachronous } \\
(\boldsymbol{n}=177)\end{array}$ & P value \\
\hline Patient characteristics & & & \\
\hline Age (years) & $58(49-67)$ & $57(48-66)$ & 0.368 \\
\hline Male gender & $137(56.4 \%)$ & $81(45.8 \%)$ & 0.032 \\
\hline Symptomatic & $185(76.1 \%)$ & $102(57.6 \%)$ & $<0.001$ \\
\hline
\end{tabular}

Primary tumor characteristics

$\begin{array}{lll}\begin{array}{c}\text { Location of } \\ \text { primary NET }\end{array} & & \\ \text { Gastrointestinal } & 117(48.1 \%) & 79(44.6 \%) \\ \text { Pancreas } & 113(46.5 \%) & 80(45.2 \%) \\ \text { Other } & 13(5.4 \%) & 18(10.2 \%)\end{array}$

$\begin{array}{ll}\text { Functional status } & 0.027\end{array}$

$\begin{array}{lll}\text { Non-functional } & 201(82.7 \%) & 159(89.8 \%) \\ \begin{array}{l}\text { Functional } \\ \begin{array}{c}\text { Grade of } \\ \text { differentiation }\end{array}\end{array} & 42(17.3 \%) & 17(9.6 \%) \\ \text { Well } & 130(53.5 \%) & 70(39.6 \%) \\ \text { Moderate } & 53(21.8 \%) & 26(14.7 \%) \\ \text { Poor } & 19(7.8 \%) & 24(13.6 \%)\end{array}$

Lymph node status

$\begin{array}{lll}\text { No } & 89(36.6 \%) & 82(46.3 \%) \\ \text { N1 } & 138(56.8 \%) & 72(40.7 \%)\end{array}$

NELM characteristics

Liver involvement

$<50 \%$

$\geq 50 \%$

46 (18.9\%)

0.671

$\begin{array}{clll}\text { Bilobar disease } & 133(54.7 \%) & 87(49.2 \%) & 0.258 \\ \begin{array}{c}\text { Extrahepatic } \\ \text { disease at } \\ \text { diagnosis }\end{array} & 22(9.1 \%) & 16(9.0 \%) & 1.000 \\ & & & \end{array}$

Surgical procedures

Types of

hepatectomy

$\begin{array}{lll}\begin{array}{l}\text { Parenchymal- } \\ \text { sparing } \\ \text { resection }\end{array} & 131(53.9 \%) & 103(58.2 \%) \\ \begin{array}{l}\text { Major resection } \\ \text { Maj }\end{array} & 1074.0 \%) & 68(38.4 \%)\end{array}$

Pre-hepatectomy

0.047 treatment

Octreotide

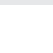

\begin{abstract}
$52(21.4 \%)$
\end{abstract}

$52(21.4 \%)$

Chemotherapy

None

Intraoperative ablation

Margin status
0.025 
TABLE 1 (Continued)

\begin{tabular}{|c|c|c|c|}
\hline & $\begin{array}{l}\text { Synchronous } \\
(n=243)\end{array}$ & $\begin{array}{l}\text { Metachronous } \\
(n=177)\end{array}$ & $P$ value \\
\hline RO & $188(77.4 \%)$ & $132(74.6 \%)$ & \\
\hline R1 & 55 (22.6\%) & 45 (25.4\%) & \\
\hline Adjuvant therapy & & & 0.066 \\
\hline Octreotide & 74 (30.5\%) & 33 (18.6\%) & \\
\hline Chemotherapy & 25 (10.3\%) & 18 (10.2\%) & \\
\hline None & 125 (51.4\%) & 99 (55.9\%) & \\
\hline
\end{tabular}

vs well differentiated, HR 3.1,95\%Cl 1.3-7.3, $P=0.009$ ) (Table 2). In addition, tumor recurrence was associated with characteristics of the primary NET (pancreatic vs gastrointestinal type, $\mathrm{HR} 1.7,95 \% \mathrm{Cl}$ 1.1-2.5, $P=0.010$; poor vs well differentiated, $\mathrm{HR} 1.6,95 \% \mathrm{Cl} 1.0-2.6$, $P=0.050$; lymph nodes metastasis, HR $2.5,95 \% \mathrm{Cl} 1.5-4.1, P<0.001$ ) and location of metastasis (extrahepatic disease, $\mathrm{HR} 2.6,95 \% \mathrm{Cl}$ 1.4-4.5, $P=0.001$ ). In multivariable analysis, after accounting for these factors, synchronous versus metachronous NELM was not associated with DSS (HR 1.3, 95\% CI 0.8-2.0, $P=0.331$ ) (Table 2), but synchronous disease presentation was independently associated with decreased RFS (HR 1.9, 95\% Cl 1.2-3.1, $P=0.005$ ) (Table 3).

\section{2 | Management of synchronous NELM: Simultaneous versus staged resection}

Among the 243 patients with synchronous NELM, three quarters of patients ( $n=181,74.5 \%$ ) underwent simultaneous resection, while one quarter ( $n=62,25.5 \%)$ underwent a staged resection. Most clinical and pathological characteristics of patients undergoing a simultaneous versus a staged resection were comparable (Table 4). Simultaneous resection of the primary NET and NELM was, however, more common among patients with a pancreatic primary NET (OR 1.4, 95\% 1.0-2.2) (Table 4). In addition, when a simultaneous resection was performed, the liver resection was more often a parenchymal-sparing/minor hepatectomy (simultaneous: $59.1 \%$ vs staged: $38.7 \%$ ); in contrast, a major hepatectomy was more often performed in the setting of a staged resection (simultaneous: $39.8 \%$ vs staged: $56.5 \% ; P=0.011$; OR 1.5, 95\% 1.1-3.9) (Table 4).

A simultaneous versus staged approach for synchronous NELM had no effect on long-term outcomes. Specifically, DSS (10-year DSS, simultaneous: $72.8 \%$ vs staged: $66.2 \%, P=0.754$; HR 0.9, $95 \%$ $\mathrm{Cl} 0.5-1.7)$ and RFS (10-year RFS, simultaneous: $34.6 \%$ vs staged: $32.8 \%, P=0.365$; HR $1.2,95 \% \mathrm{Cl} 0.8-1.8)$ were comparable regardless of operative approach (Figures $3 \mathrm{~A}$ and $3 \mathrm{~B}$ ). A subset of patients $(n=23)$ who underwent staged resection had the second procedure performed at 6 months or longer from the time of the first operation (median 4.3 months, IQR 2.1-10.5 months). There was no difference, however, in DSS (10-year DSS, <6 months: $61.0 \%$ vs $\geq 6$ months: $71.8 \%, P=0.601$; HR 0.7, 95\%Cl 0.22.3 ) or RFS (10-year RFS, <6 months: $28.3 \%$ vs $\geq 6$ months: $38.5 \%$, $P=0.624$; HR $0.8,95 \% \mathrm{Cl} 0.4-1.7)$ among patients who underwent early versus delayed staged resection of simultaneous NELM (Figures $3 \mathrm{C}$ and $3 \mathrm{D}$ ).

\section{3 | Management of metachronous NELM: Early versus delayed resection}

Among the 177 patients who developed metachronous NELM, more than half $(n=102,57.6 \%$ ) developed NELM within the first 2 years after resection of the primary NET (median time to metachronous NELM: 20 months, IQR [12-45.5 months]) (Figure 4A). On unmatched analyses, patients with early metachronous NELM had a similar DSS (10-year DSS, metachronous $<2$ years: $78.9 \%$ vs metachronous $\geq 2$ years: $71.9 \%$,
(A)

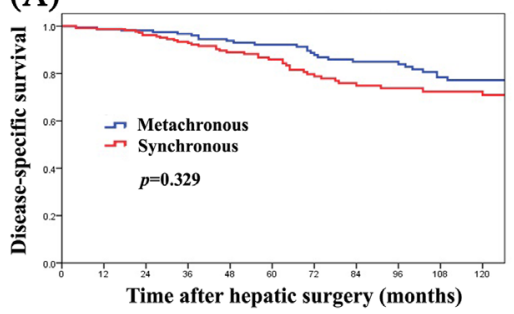

After propensity score matching

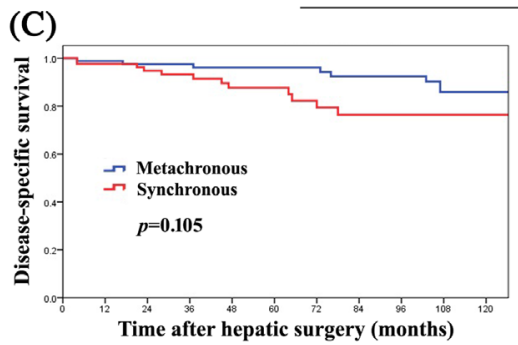

(B)

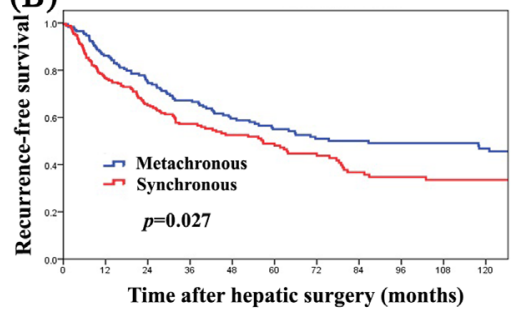

(D)

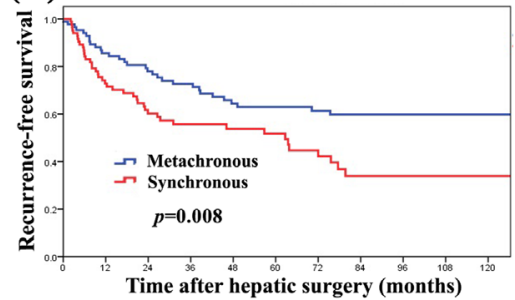

FIGURE 2 Disease-specific and recurrence-free survival after curative-intent hepatectomy for synchronous and metachronous neuroendocrine liver metastasis before $(A, B)$ and after $(C, D)$ propensity score matching 
TABLE 2 Risk factors associated with disease-specific survival of neuroendocrine tumor liver metastasis after curative-intent surgery

\begin{tabular}{|c|c|c|c|c|}
\hline \multirow[b]{2}{*}{ Parameters } & \multicolumn{2}{|c|}{ Univariate analysis } & \multicolumn{2}{|c|}{ Multivariable analysis } \\
\hline & HR $(95 \% \mathrm{Cl})$ & $P$ value & HR $(95 \% \mathrm{Cl})$ & $P$ value \\
\hline \multicolumn{5}{|l|}{ Patient characteristics } \\
\hline Gender (male/female) & $0.7(0.5-1.2)$ & 0.218 & & \\
\hline \multicolumn{5}{|l|}{ Primary tumor characteristics } \\
\hline Gastrointestinal & Ref. & & & \\
\hline Pancreas & $1.5(0.9-2.4)$ & 0.124 & & \\
\hline Other & $0.9(0.4-2.2)$ & 0.817 & & \\
\hline Functional status & & 0.025 & & 0.025 \\
\hline Well & Ref. & & Ref. & \\
\hline Moderate & $1.9(0.9-4.1)$ & 0.095 & $1.3(0.6-3.2)$ & 0.512 \\
\hline Poor & $2.0(1.0-3.9)$ & 0.039 & $3.1(1.3-7.3)$ & 0.009 \\
\hline Lymph node status & & 0.001 & & 0.161 \\
\hline NO & Ref. & & Ref. & \\
\hline N1 & $2.5(1.5-4.2)$ & & $1.8(0.8-3.9)$ & \\
\hline \multicolumn{5}{|l|}{ Liver metastases characteristics } \\
\hline Synchronous vs metachronous & $1.3(0.8-2.0)$ & 0.331 & & \\
\hline Types of hepatectomy & & 0.002 & & 0.937 \\
\hline Parenchymal-sparing resection & Ref. & & Ref. & \\
\hline Major resection & $0.5(0.3-0.7)$ & & $1.0(0.4-2.4)$ & \\
\hline Margin status & & 0.010 & & 0.931 \\
\hline RO & Ref. & & Ref. & \\
\hline $\mathrm{R} 1$ & $1.9(1.2-3.1)$ & & $1.0(0.5-2.3)$ & \\
\hline
\end{tabular}

$P=0.188$; HR 0.6, 95\% Cl 0.3-1.3), yet a more favorable RFS (metachronous <2 years: $58.4 \%$ vs metachronous $\geq 2$ years: $18.5 \%, P=0.003$; HR $0.5,95 \% \mathrm{Cl}$ 0.3-0.8) (Figures 4A and 4B; Supplementary Table S2). On propensity score matching, there was no difference in long-term outcomes among patients with early versus late metachronous NELM (10-year DSS, metachronous < 2 years: $60.8 \%$ vs metachronous $\geq 2$ years: 77.0\%, $P=0.395$; HR 1.4, 95\%Cl 0.6-3.2) (10-year RFS, metachronous <2 years: $42.5 \%$ vs metachronous $\geq 2$ years: $18.1 \%, P=0.632 ; \mathrm{HR} 0.9,95 \% \mathrm{Cl}$ 0.5-1.5) (Figures 4D and 4E; Supplementary Table S3).

Of note, among patients with metachronous NELM, a delay in hepatic resection did not have an effect on long-term outcomes. Specifically, patients who had hepatic resection $<6$ months $(n=110)$ following the diagnosis of metachronous disease had comparable long-term outcomes as patients with metachronous NELM who had a stage resection $\geq 6$ months ( $n=60$ ) (10-year DSS, $<6$ months: $81.7 \%$ vs $\geq 6$ months: $66.3 \% ; P=0.219$; HR 0.8, 95\%Cl 0.3-1.9) (10-year RFS, $<6$ months: $50.1 \%$ vs $\geq 6$ months: $38.5 \%, P=0.294$; $\mathrm{HR} 0.9,95 \% \mathrm{Cl}$ $0.5-1.6$ ) (Figures $4 \mathrm{~F}$ and $4 \mathrm{G}$ ).

\section{DISCUSSION}

Timing of disease presentation and its impact on long-term outcomes, as well as the optimal timing of hepatic resection, remain poorly 
TABLE 3 Risk factors associated with recurrence-free survival of neuroendocrine tumor liver metastasis after curative-intent surgery

\begin{tabular}{|c|c|c|c|c|}
\hline \multirow[b]{2}{*}{ Parameters } & \multicolumn{2}{|c|}{ Univariate analysis } & \multicolumn{2}{|c|}{ Multivariable analysis } \\
\hline & HR (95\%Cl) & $P$ value & HR (95\%Cl) & $P$ value \\
\hline \multicolumn{5}{|l|}{ Patient characteristics } \\
\hline Gender (male/female) & $1.0(0.7-1.3)$ & 0.842 & & \\
\hline \multicolumn{5}{|l|}{ Primary tumor characteristics } \\
\hline Gastrointestinal & Ref. & & Ref. & \\
\hline Pancreas & $1.3(1.0-1.8)$ & 0.049 & $1.7(1.1-2.5)$ & 0.010 \\
\hline Other & $0.5(0.2-0.9)$ & 0.032 & $0.5(0.2-1.8)$ & 0.297 \\
\hline Functional status & & 0.006 & & 0.317 \\
\hline Well & Ref. & & Ref. & \\
\hline Moderate & $1.5(1.0-2.2)$ & 0.062 & $1.4(0.8-2.4)$ & 0.234 \\
\hline Poor & $1.6(1.0-2.5)$ & 0.040 & $1.6(1.0-2.6)$ & 0.050 \\
\hline Lymph node status & & $<0.001$ & & $<0.001$ \\
\hline NO & Ref. & & Ref. & \\
\hline N1 & $3.1(2.2-4.3)$ & & $2.5(1.5-4.1)$ & \\
\hline \multicolumn{5}{|l|}{ Liver metastases characteristics } \\
\hline Synchronous vs metachronous & $1.4(1.0-1.8)$ & 0.027 & $1.9(1.2-3.1)$ & 0.005 \\
\hline Types of hepatectomy & & $<0.001$ & & 0.006 \\
\hline Parenchymal-sparing resection & Ref. & & Ref. & \\
\hline Major resection & $0.4(0.3-0.5)$ & & $0.5(0.3-0.8)$ & \\
\hline Margin status & & $<0.001$ & & 0.077 \\
\hline RO & Ref. & & Ref. & \\
\hline $\mathrm{R} 1$ & $1.9(1.4-2.6)$ & & $1.5(1.0-2.2)$ & \\
\hline
\end{tabular}

defined in the treatment of NELM. The current study was important because it specifically defined outcomes among a large group of patients with NELM relative to disease presentation (synchronous vs metachronous) and operative approach (simultaneous vs staged). Using a multi-institutional cohort, we demonstrated that patients who presented with synchronous NELM had a worse post-surgical longterm RFS compared with patients with metachronous NELM. In contrast, the type of operative approach (simultaneous vs staged) was associated with similar long-term RFS and DSS for patients with synchronous NELM. Furthermore, a 6 month delay in performing hepatic resection appeared to have no detrimental effect on survival among patients with synchronous NELM. Among patients with metachronous disease, although more than one half developed metastasis within the first 2 years, the survival of patients with early versus late metachronous disease was comparable.

Among patients with NET, approximately $50 \%$ of patients will present with synchronous NELM, while the other half develop metachronous NELM during the course of their disease. ${ }^{22,23}$ In the current study, there was a slightly higher predominance of patients who presented with synchronous disease $(57.9 \%)$ versus metachronous disease (42.1\%). The impact of disease presentation has been well studied in the setting of CRLM. ${ }^{12,24,25}$ Most surgeons agree that synchronous disease is an indicator of poor prognosis independent of treatment. ${ }^{12,24,26}$ Data from Adam et al from the LiverMetSurvey, an 
TABLE 4 Clinical and pathological characteristics of patients undergoing simultaneous and staged hepatic resection for synchronous neuroendocrine liver metastasis (NELM)

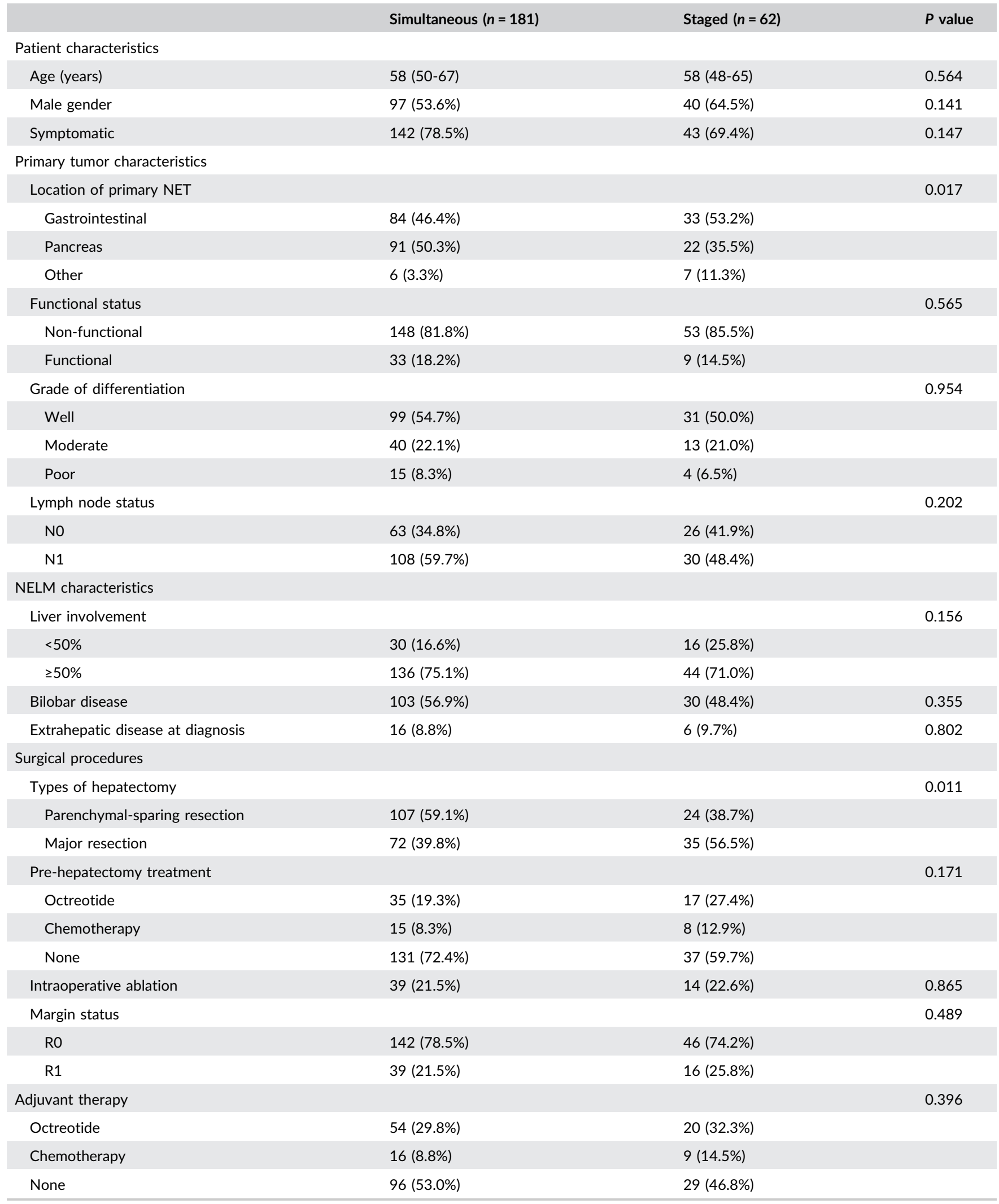


(A)

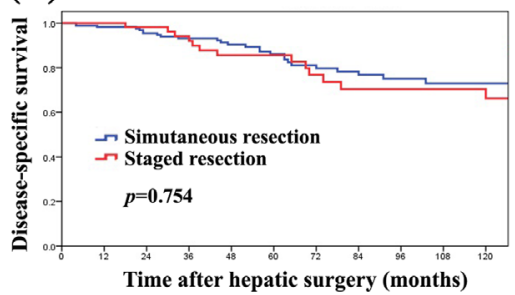

(C)

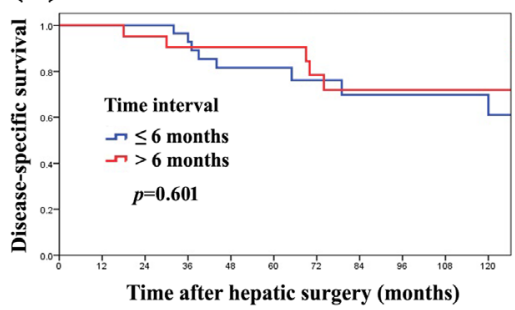

(B)

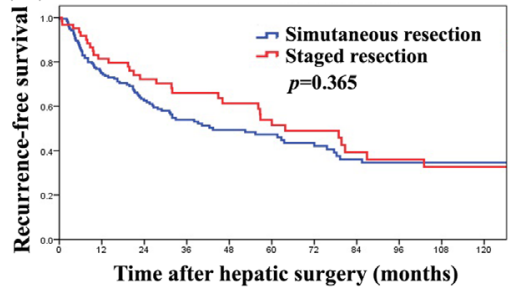

(D)

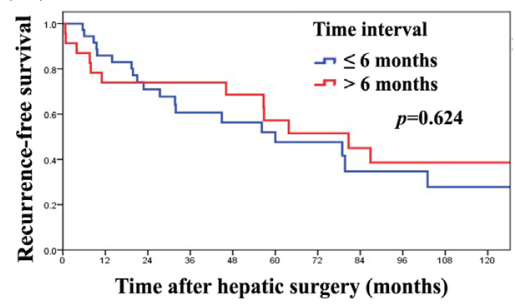

FIGURE 3 Outcome of patients after hepatic resection for synchronous neuroendocrine liver metastasis (NELM). A and B, Disease-specific and recurrence-free survival of synchronous NELM following simultaneous or staged hepatic resection. C and D, Disease-specific and recurrence-free survival of patients undergoing staged resection of NELM within or beyond 6 months after primary surgery

international registry of patients undergoing surgery for CRLM, demonstrated a significant difference in survival when CRLM were detected at or 1 month within diagnosis of the primary tumor versus $>3$ months after diagnosis. ${ }^{12}$ In addition, in probably the most widely utilized prognostic scoring scheme for CRLM, the Clinical Risk Score (ie, "Fong" score) incorporates synchronous disease as one of the prognostic factors. ${ }^{10}$ In contrast, the impact of disease presentation (ie, synchronous vs metachronous) on the prognosis of patients with NELM has been less studied. While several studies have suggested that synchronous NELM may adversely impact outcomes, disease presentation was not the specific focus on these analyses. ${ }^{3,9,27,28}$ Unlike previous studies that did not utilized statistical techniques to control for potential biases affecting disease presentation, the current study employed both multivariable analyses and PSM to adjust for differences in baseline characteristics between groups. Specifically, by using PSM variables to balance factors potentially affecting long-term outcomes, we were able to create comparable groups of patients who had synchronous versus metachronous disease (Supplementary Table S1). These analyses demonstrated that synchronous NELM was associated with a worse RFS after curative-intent hepatic resection compared with patients who had metachronous disease. In fact, on PSM, patients who presented with synchronous disease had an $80 \%$ increased risk of having recurrence at 10 years versus individuals who developed metachronous disease $(\mathrm{HR} 1.8,95 \% \mathrm{Cl}$ 1.2-2.9; Figure 2D).

Among patients with synchronous disease, the operative approach has also been a topic of much debate. For patients with CRLM, the classic approach to surgery of synchronous disease was to perform primary surgery of the primary colorectal tumor followed by resection of the CRLM after an interval of time. ${ }^{14,15,29}$ Some surgeons had traditionally recommended a delay in hepatic resection for 3-6 months as this "waiting time" might allow for occult hepatic disease to become detectable, and thus avoid an "unnecessary" hepatic resection. ${ }^{16,17,29-32}$ Contemporary data and clinical thinking, however, has refuted this notion. In fact, multiple studies have demonstrated that simultaneous surgery of the primary and CRLM was safe and led to the same long-term survival outcomes. ${ }^{14,18-20,33}$ In fact, simultaneous surgery has been advocated as being the preferred approach for some patients with CRLM, as it eliminates the need for a second surgery and decreases both length of stay and health care costs. ${ }^{14,18-20,33}$ In the current study, a simultaneous versus staged approach for synchronous NELM had no effect on long-term outcomes. Specifically, DSS and RFS were comparable regardless of operative approach (Figures $3 \mathrm{~A}$ and $3 \mathrm{~B}$ ). As such, similar to patients with CRLM, the data would suggest that a simultaneous approach to synchronous NELM may be preferable. For those patients with synchronous NELM who do undergo a staged approach, the timing of the second operation may not impact long-term outcomes. Specifically, the subset of patients who underwent staged resection at 6 months or longer from the time of the first operation had no difference in DSS or RFS versus patients who underwent an earlier resection of simultaneous NELM (Figures 3C and 3D). Collectively, these data strongly suggest that, while synchronous NELM disease presentation is associated with long-term outcomes, operative strategy regarding the timing of surgical management (simultaneous vs staged) does not impact prognosis.

Almost one half of patients develop metachronous NELM after curative resection of primary $\mathrm{NET}, 3,14,22,23$ yet the clinical characteristics, treatment, and prognosis of metachronous NELM have not been specifically defined. Of note, based on a time course analysis, we noted that the majority (57.6\%) of metachronous NELM was detected within the first 2 years following primary resection. On unadjusted analyses, patients who developed early metachronous NELM had a decreased incidence of recurrence, yet comparable DSS versus patients who had late NELM. However, in the matched cohort analysis, there was no 


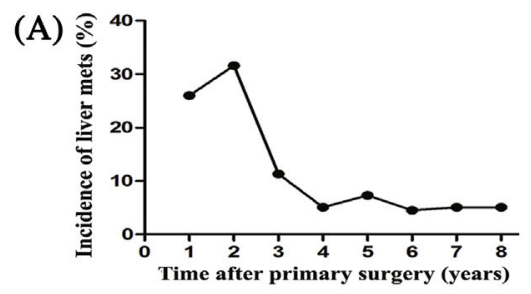

(B)

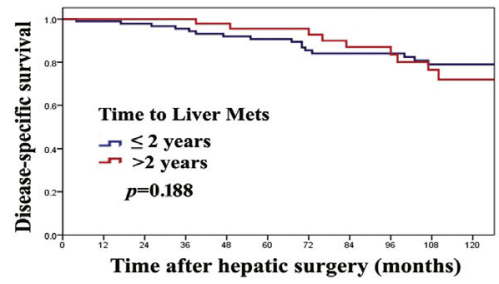

(C)

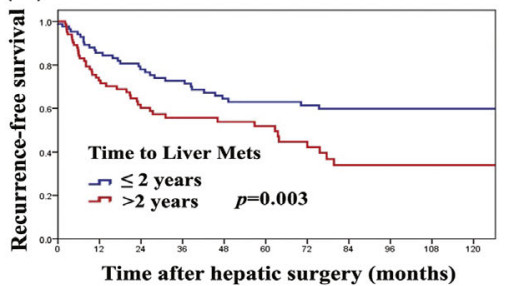

After propensity score matching

(D)

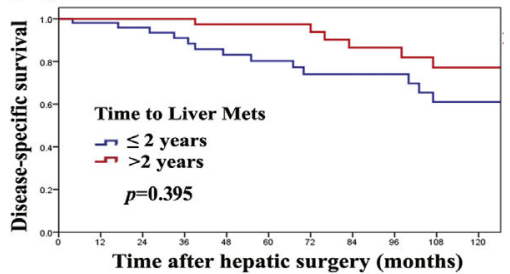

(F)

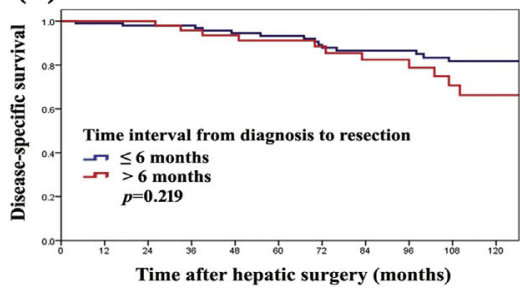

(E)

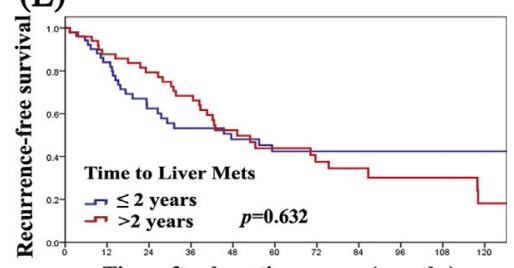

Time after hepatic surgery (months)

(G)

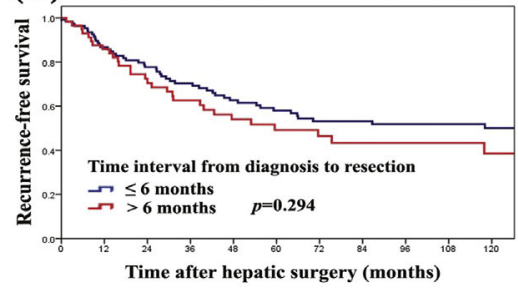

FIGURE 4 Outcome of patients undergoing hepatic resection for metachronous neuroendocrine liver metastasis (NELM). A, Timing and incidence of metachronous neuroendocrine liver metastasis (NELM). B and C, Disease-specific and recurrence-free survival of early ( $\leq 2$ years after primary surgery) and late ( $>2$ years after primary surgery) metachronous NELM after hepatic resection. D and E, Disease-specific and recurrence-free survival of early and late metachronous NELM after hepatic resection in the propensity model. F and G, Outcome of patients after a delayed ( $>6$ months after diagnosis) and non-delayed ( $\leq 6$ months after diagnosis) hepatic surgery

difference in RFS or DSS among patients who had early versus late metachronous NELM groups. Therefore, timing of disease occurrence itself did not influence the prognosis of patients with metachronous NELM. Similar to synchronous NELM, the operative management of metachronous disease has been debated.

To evaluate the assumption that occult liver metastasis might be found during a "waiting period," Ueno et al evaluated a 3-months delay of hepatic resection on the long-term outcome of patients with metachronous CRLM. ${ }^{34}$ In this study, the authors concluded that delayed liver resection for metachronous CRLM had no clinical benefit. Building on this work, we sought to examine whether a delayed approach to liver resection for patients with metachronous NELM would have clinical utility. Patients who underwent hepatic resection with a delay of more than 6 months after detection of metachronous NELM had comparable long-term survival as patients who received immediate hepatic resection within 6 months. These findings may be helpful to patients and providers as the data demonstrate that a delay of resection for a moderate time period ( $\sim 6$ month) does not affect long-term survival-likely due to the slow-growing nature and long natural history of most NELM. ${ }^{34,35}$

The present study had several limitations. Given the retrospective nature of the study, selection bias was likely. However, unlike many previous studies, we utilized propensity score matching to create groups that were well-matched on baseline characteristics to mitigate any selection bias. Moreover, "disease occurrence" was defined based on "disease detection;" therefore, a delayed or missed identification of liver metastasis due to technical problems, or lower patient compliance with regards to postoperative follow-up could not be completely excluded. Additionally, this multi-institutional database did not contain data on perioperative complications or socioeconomic status, and we were therefore unable to assess short-term outcomes or healthcare costs.

In conclusion, patients with synchronous NELM had a higher risk of tumor recurrence after hepatic resection versus patients with 
metachronous disease. Simultaneous resection of synchronous disease may be preferred, as it results in equivalent long-term survival versus staged resection. The time to development of metachronous NELM did not affect long-term outcome, and therefore a curativeintent hepatic resection should be considered for patients who develop NELM at any time following resection of primary NET.

\section{ACKNOWLEDGMENT}

X.-F. Z. was supported in part by the China Scholarship Council.

\section{AUTHORS' CONTRIBUTIONS}

Study design, XF Zhang, TM Pawlik; Data collection and interpretation, EW Beal, Yi Lv, J Chakedis, F Bagante, D Moris, L Aldrighetti, GA Poultsides, TW Bauer, RC Fields, SK Maithel, HP Marques, M Weiss; Data analysis, XF Zhang, EW Beal, Y Lv, Chakedis, F Bagante; Drafting, XF Zhang, EW Beal; Revision of the draft: EW Beal, TM Pawlik.

\section{CONFLICTS OF INTEREST}

None.

\section{ORCID}

Eliza W. Beal iD http://orcid.org/0000-0003-2191-6811

Matthew Weiss iD http://orcid.org/0000-0003-0553-248X

Timothy M. Pawlik iD http://orcid.org/0000-0002-4828-8096

\section{REFERENCES}

1. Farley HA. Pommier RF treatment of neuroendocrine liver metastases. Surg Oncol Clin N Am. 2016;25:217-225.

2. Spolverato G, Bagante F, Wagner D, et al. Quality of life after treatment of neuroendocrine liver metastasis. J Surg Res. 2015;198:155-164.

3. Spolverato G, Bagante F, Aldrighetti L, et al. Management and outcomes of patients with recurrent neuroendocrine liver metastasis after curative surgery: an international multi-institutional analysis. J Surg Oncol. 2017.

4. Yao JC, Hassan M, Phan A, et al. One hundred years after "carcinoid": epidemiology of and prognostic factors for neuroendocrine tumors in 35,825 cases in the United States. J Clin Oncol. 2008;26:3063-3072.

5. Frilling $A$, Clift $A K$. Therapeutic strategies for neuroendocrine liver metastases. Cancer. 2015;121:1172-1186.

6. Frilling A, Modlin IM, Kidd M, et al. Recommendations for management of patients with neuroendocrine liver metastases. Lancet Oncol. 2014;15:8-21.

7. Rindi G, D'Adda T, Froio E, et al. Prognostic factors in gastrointestinal endocrine tumors. Endocr Pathol 2007;18:145-149.

8. Jones NB, Shah MH. Bloomston M Liver-directed therapies in patients with advanced neuroendocrine tumors. J Natl Compr Canc Netw. 2012;10:765-774.

9. Spolverato G, Vitale A, Ejaz A, et al. Net health benefit of hepatic resection versus intraarterial therapies for neuroendocrine liver metastases: a Markov decision model. Surgery. 2015;158:339-348.

10. Fong Y, Fortner J, Sun RL, et al. Clinical score for predicting recurrence after hepatic resection for metastatic colorectal cancer: analysis of
1001 consecutive cases. Ann Surg. 1999;230:309-318. Discussion 318-321.

11. Adam R, Frilling A, Elias D, et al. Liver resection of colorectal metastases in elderly patients. Br J Surg. 2010;97:366-376.

12. Adam R, de Gramont A, Figueras J, et al. Managing synchronous liver metastases from colorectal cancer: a multidisciplinary international consensus. Cancer Treat Rev. 2015;41:729-741.

13. Manfredi S, Lepage $C$, Hatem C, et al. Epidemiology and management of liver metastases from colorectal cancer. Ann Surg. 2006;244:254-259.

14. Mayo SC, Pulitano C, Marques $\mathrm{H}$, et al. Surgical management of patients with synchronous colorectal liver metastasis: a multicenter international analysis. J Am Coll Surg 2013;216:707-716. Discussion 716-708.

15. Ejaz A, Semenov E, Spolverato G, et al. Synchronous primary colorectal and liver metastasis: impact of operative approach on clinical outcomes and hospital charges. HPB (Oxford). 2014;16:1117-1126.

16. Nordlinger B, Guiguet $M$, Vaillant JC, et al. Surgical resection of colorectal carcinoma metastases to the liver. A prognostic scoring system to improve case selection, based on 1568 patients. Association Francaise de Chirurgie. Cancer. 1996;77:1254-1262.

17. Bolton JS, Fuhrman GM. Survival after resection of multiple bilobar hepatic metastases from colorectal carcinoma. Ann Surg. 2000;231: 743-751.

18. Yoshioka R, Hasegawa K, Mise $\mathrm{Y}$, et al. Evaluation of the safety and efficacy of simultaneous resection of primary colorectal cancer and synchronous colorectal liver metastases. Surgery. 2014;155:478-485.

19. Martin RC, 2nd, Augenstein V, Reuter NP, et al. Simultaneous versus staged resection for synchronous colorectal cancer liver metastases. J Am Coll Surg. 2009;208:842-850. Discussion 850-842.

20. Silberhumer GR, Paty PB, Denton B, et al. Long-term oncologic outcomes for simultaneous resection of synchronous metastatic liver and primary colorectal cancer. Surgery. 2016;160:67-73.

21. Yin Z, Liu C, Chen Y, et al. Timing of hepatectomy in resectable synchronous colorectal liver metastases (SCRLM): Simultaneous or delayed? Hepatology. 2013;57:2346-2357.

22. Chamberlain RS, Canes D, Brown KT, et al. Hepatic neuroendocrine metastases: does intervention alter outcomes? J Am Coll Surg. 2000;190:432-445.

23. Mayo SC, de Jong MC, Pulitano C, et al. Surgical management of hepatic neuroendocrine tumor metastasis: results from an international multi-institutional analysis. Ann Surg Oncol. 2010;17: 3129-3136.

24. de Jong MC, Pulitano C, Ribero D, et al. Rates and patterns of recurrence following curative intent surgery for colorectal liver metastasis: an international multi-institutional analysis of 1669 patients. Ann Surg. 2009;250:440-448.

25. Reddy SK, Zorzi D, Lum YW, et al. Timing of multimodality therapy for resectable synchronous colorectal liver metastases: a retrospective multi-institutional analysis. Ann Surg Oncol. 2009;16:1809-1819.

26. Ali SM, Pawlik TM, Rodriguez-Bigas MA, Monson JR, Chang GJ, Larson DW. Timing of surgical resection for curative colorectal cancer with liver metastasis. Ann Surg Oncol. 2017. https://doi.org/ 10.1245/s10434-016-5745-7. [Epub ahead of print].

27. Sarmiento JM, Heywood G, Rubin J, et al. Surgical treatment of neuroendocrine metastases to the liver: a plea for resection to increase survival. J Am Coll Surg. 2003;197:29-37.

28. Mayo SC, Herman JM, Cosgrove D, et al. Emerging approaches in the management of patients with neuroendocrine liver metastasis: role of liver-directed and systemic therapies. J Am Coll Surg. 2013;216:123-134.

29. Yoshidome H, Kimura F, Shimizu H, et al. Interval period tumor progression: does delayed hepatectomy detect occult metastases in synchronous colorectal liver metastases? J Gastrointest Surg. 2008;12: 1391-1398.

30. Kaibori $M$, Iwamoto $S$, Ishizaki $M$, et al. Timing of resection for synchronous liver metastases from colorectal cancer. Dig Dis Sci. 2010;55:3262-3270. 
31. Inoue $\mathrm{Y}$, Imai $\mathrm{Y}$, Osumi $\mathrm{W}$, et al. What is the optimal timing for liver surgery of resectable synchronous liver metastases from colorectal cancer? Am Surg. 2017;83:45-53.

32. Capussotti L, Vigano L, Ferrero A, et al. Timing of resection of liver metastases synchronous to colorectal tumor: proposal of prognosisbased decisional model. Ann Surg Oncol. 2007;14:1143-1150.

33. Abelson JS, Michelassi F, Sun T, et al. Simultaneous resection for synchronous colorectal liver metastasis: the new standard of care? J Gastrointest Surg. 2017;21:975-982.

34. Ueno $S$, Sakoda $M$, Kitazono $M$, et al. Is delayed liver resection appropriate for patients with metachronous colorectal metastases? Ann Surg Oncol. 2011;18:1104-1109.

35. Elias D. Impact of tumor doubling time on the therapeutic strategy: application to so-called synchronous metastases of colorectal cancers. Ann Chir. 1998;52:413-420.

\section{SUPPORTING INFORMATION}

Additional Supporting Information may be found online in the supporting information tab for this article.

How to cite this article: Zhang X-F, Beal EW, Weiss M, et al. Timing of disease occurrence and hepatic resection on longterm outcome of patients with neuroendocrine liver metastasis. J Surg Oncol. 2018;117:171-181.

https://doi.org/10.1002/jso.24832 